\title{
Well-Being, Job Satisfaction and Labour Mobility.
}

\author{
Francis Green.
}

\begin{abstract}
I investigate whether two indicators of job-related well-being predict subsequent quitting. I find that both the Depression-Enthusiasm scale and the Anxiety-Comfort scale predict quitting, the former more strongly, and this contributes an element of criterion validity to their use as welfare measures. However, overall job satisfaction, which implicitly captures well-being relative to outside job opportunities, predicts job mobility better than either the Depression-Enthusiasm or the Anxiety-Comfort scale. I also find asymmetric effects: relative to intermediate levels, low well-being or job satisfaction are associated with greater quitting, yet high well-being or job satisfaction are not significantly associated with reduced quitting.
\end{abstract}

Key words: quits, turnover, well-being, depression, anxiety. 


\section{Well-Being, Job Satisfaction and Labour Mobility}

\section{Introduction.}

Well-being measures are increasingly being developed in economic analysis (Kahneman and Krueger, 2006), and are set to form a focal point for applied welfare analyses in several fields. However, their use in labour economics has so far largely been confined to the study of job satisfaction. This paper investigates whether the concept of job-related well-being could be a useful indicator. Although the analysis of well-being can be justified in itself, even if it does not correspond closely to decision utility, labour economists would feel naturally uneasy targeting an indicator that had no relation to workers' choices. Understanding how job-related well-being is related to labour mobility should therefore be of interest, not only in itself but also as an element in the criterion validation of the indicators used. The contribution of this paper is to provide evidence on whether measures of job-related affective well-being are significant predictors of labour mobility; and if so, whether they are better, or worse, predictors than job satisfaction. I do this using representative data in Britain.

\section{Framework and Specification.}

The motivation for this exercise is similar to that which drove the introduction of the "job satisfaction" indicator into labour economics since the 1970s (Freeman, 1978; Hamermesh, 1977). Though job satisfaction was regarded as a "soft" subjective variable, the robust finding that it was related to quitting intentions and behaviour made the case for a research agenda. Social surveys and many firms were collecting job satisfaction data, so the tools were becoming available. Research focused in part on the relationships of particular facets of job satisfaction to quitting (Clark, 2001; Clark et al., 1998). The 
attraction of this agenda was the aspiration that job satisfaction could provide a direct measure of utility from work, and a number of writers have used job satisfaction as a measure of job quality. Thus, when the quality of work came to the fore at the start of this decade in policy circles, for example as part of the "Lisbon agenda" for the European Union, aggregate indicators of job satisfaction were looked to as potential indicators for an assessment for employment policies (e.g. European Economy, 2002). Studies focused also on the determinants of job satisfaction, extending with economists' methods a longer tradition within psychology (Weir, 1977). Yet, the interpretation of job satisfaction has proved more complex, and the course of research has been that of an indicator in search of its parent concept. Job satisfaction's relationship to "utility" crucially depends on the comparison point and standard, against which survey respondents judge their degree of satisfaction. Strands of job satisfaction research have focused on identifying the relevant comparison norms - colleagues, neighbours, similar workers, past experience or current alternatives. Levy-Garboua et al. (2004, 2007), for example, argue that a person's job satisfaction is in effect an evaluation, an "experienced or post-decisional preference for her job relative to outside opportunities" (2007: p.252). Kristensen and Johansson (2008) find that different comparison standards across countries render uncertain how one should interpret cross-cultural comparisons of job satisfaction. Nevertheless, even though job satisfaction is not a direct indicator for either utility or job quality, it does convey some indirect partial information about workers' preferences. ${ }^{1}$

In principle, job-related well-being, a long-standing concept within psychological research, should also be applicable within labour economics, and might be a better proxy measure of utility from work. Unlike job satisfaction, subjective well-being does not

\footnotetext{
${ }^{1}$ Hamermesh (2001), for example, concludes: "even though it may be a substantial stretch to link expressed job satisfaction (or satisfaction generally) to utility, studying job satisfaction is still important for understanding labor-market behavior ...".
} 
reflect evaluation and comparison with the utility derivable from some alternative state. ${ }^{2}$ Moreover, indicators of job-related well-being are designed to be more general than job satisfaction. The theory of well-being hypothesises that the generic range of emotions or feelings can be summarised by descriptions of their location along (at least) two orthogonal dimensions, one covering the degree of pleasure or displeasure being experienced, the other the degree of arousal (e.g. Russell, 2003; Warr, 1990, 2007). Within this two-dimensional plain, well-being indicators are proposed along two axes, one ranging from "Depression" (displeasure and low arousal) to "Enthusiasm" (pleasure and high arousal), the other ranging from "Anxiety" (displeasure and high arousal) to "Comfort" (high pleasure and low arousal). The indicator of job satisfaction is seen as lying along the pleasure dimension alone (Warr, 2007: p.432), implying that it is positively correlated with both the depression-enthusiasm axis and the anxiety-comfort axis, but not capturing the extent of arousal. These factors imply, at first sight, that wellbeing indicators might be a superior basis to job satisfaction for empirical welfare and policy analysis in the labour market, because they explicitly capture both the pleasure dimension and the arousal dimension, each with discriminating antecedents and effects.

Job-related well-being indicators tend to have predictable antecedents, as the psychological literature attests. For example, Totterdell et al. (2006) show that high work demands generate low levels of job-related well-being, as measured by either the Depression-Enthusiasm or the Anxiety-Comfort indicator. However, to warrant using them in labour market analysis we desire also that they can predict behaviours. In support there is, for example, evidence that subjective well-being is associated with subsequent absence behaviour (e.g. Hardy et al., 2003). Absence indicators are related more strongly to scores on the Depression-Enthusiasm axis than to job satisfaction or to scores on the

\footnotetext{
2 Despite this, it can be recognised that emotional states may nevertheless be influenced by comparisons with alternatives.
} 
Anxiety-Comfort axis (Warr, 2007: p. 430). There are also several studies that find associations between job-related well-being and other indicators of job performance, though in most cases the direction of causality is not established. For a review of this infant literature, see Warr (2007: Ch. 14). Some well-being scales are also known to have strong relationships with objective indicators of mental ill-health. ${ }^{3}$

One can also expect an impact of well-being on job mobility. Suppose that workers are able to compare their current happiness with their prospective feelings should they quit for another job. Conditional on what the best alternative job offers, we should expect workers experiencing higher subjective well-being from their current job to be less likely to want to quit. Hence, a negative relationship with quitting is expected. Does evidence support a negative link with voluntary job mobility? Wright and Cropanzano (1998) showed a link between an emotional exhaustion scale and subsequent voluntary turnover, but this small-scale study comprised just 52 employees, all social welfare officers. Otherwise, little or nothing is known about whether job-related well-being is, like job satisfaction, related to mobility.

Whether job-related well-being indicators are expected to be better than job satisfaction as predictors of job mobility is an additional issue. As stated above, job satisfaction does not pick up respondents' location along the arousal axis of well-being, and so might on this count be expected to perform less well as a predictor than well-being scales that do. However, job satisfaction measures are not just measures of well-being along the pleasure axis. Rather, they are evaluations against alternatives which are, arguably, respondents' outside job opportunities, precisely the comparison relevant for decision-making about job mobility (Levy-Garboua and Montmarquette, 2004). ${ }^{4}$ Job satisfaction is thus

\footnotetext{
${ }^{3}$ Elliott et al. (2003) is just one example taken from a considerable literature.

${ }^{4}$ Levy-Garboua et al. (2007) propose that the quit propensity is most closely captured by the predicted residual of their job satisfaction equation, using longitudinal data.
} 
associated with the propensity to quit for one of the available alternatives. Thus, job satisfaction could be expected to be a better predictor of quitting than well-being scales that do not involve any comparative judgement. Moreover, measures of job satisfaction in surveys often have a more cognitive emphasis which may capture part of happiness as self-validation, or an evaluation by "the remembering self" (Kahneman and Riis, 2005) that is able to include a future perspective. Measures of job-related well-being are, by contrast, often indicators of experienced utility and depending on item formulation may be variable due to temporary variation. Thus job satisfaction, providing that it is reasonably accurately reported by the remembering self, might provide a closer correlate of behaviours that require major, future-oriented, decision-taking.

There is thus an ambiguity in the expectation. Job-related well-being scales might be superior as indicators of welfare at work, and therefore also might have more bite for the rational decision-maker (and hence the policy-maker), than job satisfaction. But when it comes to predicting quit behaviour, a job satisfaction indicator could still have the edge because it implicitly incorporates a comparative evaluation with alternatives, and because of its reflective character.

Formally, let us suppose that workers' perceived well-being is used to guide the decision to leave one's job. Then the probability of quitting is given by:

$\operatorname{Pr}($ Leave $)=f\left(w^{*}-w-c\right), f^{\prime}>0$

where $w$ stands for well-being, * signifies the outside job opportunity, and $c$ is the mobility cost associated with market imperfections. The decision to quit depends on how the worker perceives outside opportunities and mobility costs. Absent any direct indicators of these, a reasonably flexible assumption is that the outside opportunity is a function of personal characteristics. With the addition of job characteristics, which could 
also capture variability in mobility cost, and after linearising, a suitable model specification for the latent propensity to quit a job, $L^{*}$, is :

$L^{*}=\alpha w+\beta X+\varepsilon$

Model (A)

where $X$ is job and personal characteristics, $\varepsilon$ is a random error term. A criterion validity test of a well-being indicator, then, is the test of the hypothesis that $\alpha$ is negative.

By contrast, as discussed above job satisfaction may be conceived as directly incorporating the workers' estimate of the difference in well-being between the current and the outside job. However, incorporating mobility costs means one still has to control for personal and job characteristics. Hence, the alternative model is:

$L^{*}=\alpha J S+\beta X+\varepsilon$

Model (B)

There are thus two central research questions being addressed, each for the first time: whether work-related well-being indicators have a negative association with the propensity to quit, and whether they might even be better predictors than a more traditional job satisfaction indicator. The strategy is first to test for each well-being indicator the hypothesis that $\alpha$ is negative, and second to investigate which model best fits the data.

\section{Data and Method.}

The data are taken from the 2001 Skills Survey, details of which are given in Felstead et al. (2002). The survey targeted employed individuals aged 20 to 60 in Britain, and achieved a representative sample of 4,470 (66\% gross response rate) using face-to-face interviews conducted in people's homes. There was also a short follow-up postal survey, 
undertaken approximately 15 months after the date of interview in 2001 , covering the majority but not all respondents. The purpose of the follow-up postal survey was primarily to re-establish contact with respondents but the opportunity was taken to ask a few questions on recent employment experiences.

Some respondents refused permission to make re-contact at the time of the 2001 interview, while others failed to respond to the postal questionnaire. Out of 4005 employees in the original sample, altogether 2,913 replied at the follow-up stage with usable information on mobility status. Sample attrition was rather greater for younger workers: for those under 40 , the attrition rate was $34 \%$, while for the over 40 s it was $20 \%$. This attrition raises the issue of whether coefficient estimates could be biased by selective inclusion in the sample. To address this issue I adopt two complementary strategies. First, I restrict the sample to those over 40, with the lower attrition rate. This is sensible since the primary objective of the paper is to provide a validity test of the subjective well-being variables, rather than to provide estimates for welfare analysis purposes applicable to all employees. Second, to correct for possible selection biases among the over 40s sample I estimate models (1) and (2) using the Heckman maximum likelihood selection model.

I constructed a quit status variable as follows. "Stayers" were those still in the same job at the time of the follow-up sample. "Quitters" were those who were no longer employed in the same job but had had no intervening unemployment. The overall quit rate in the sample was $8.65 \%$. This category represents a close approximation to the category of voluntary turnover, but it might also include some involuntary turnover, and might miss a smaller number of workers who quit voluntarily into unemployment. Those who were no longer employed in the same job while having experienced some unemployment since 2001 interview were treated as missing, for the purposes of the analyses reported below, 
since it is not known whether these might have quit if they had not been made unemployed. Alternatives are to allocate this category to a quitting or non-quitting status, or to analyse this as a third mobility status. For robustness I report below the consequence of taking these alternative approaches.

A particular merit of this survey for current purposes is that, in addition to rich data on many aspects of respondents' jobs, there are indicators of job-related subjective wellbeing involving both an overall measure of job satisfaction, and items to construct two Warr scales measuring job-related well-being along the Depression-Enthusiasm and the Anxiety-Comfort axes. It is therefore possible to allow these well-being indicators to go head to head in accounting for quitting behaviour, framed by the models outlined above. The items consist of a series of adjectives describing affective states, in response to the stem: "Thinking of the past few weeks, how much of the time has your job made you feel each of the following?" (a 6-point answer scale is provided). In the case of the Depression-Enthusiasm scale the individual states are: enthusiastic, cheerful, depressed, gloomy, miserable, optimistic; for the Anxiety-Comfort scale they are: calm, tense, contented, relaxed, uneasy, worried. The two scales were computed as averages of the responses (with negative items reversed), ranging from 1 to $6 .^{5}$

The distributions of the two axes of well-being and of overall job satisfaction are summarised in Table 1. The mean values of Depression-Enthusiasm and of AnxietyComfort in this sample are 4.36 and 3.76 respectively. ${ }^{6}$ There is, however, a considerable variation around these means. The Depression-Enthusiasm scale also carries a substantive negative skewness: this means that among the low well-being jobs on this scale there are is a notable minority with especially low well-being, as illustrated in the Kernel

\footnotetext{
5 The Cronbach's alpha statistics for internal consistency of the scales were 0.804 and 0.813 respectively, which are normally considered acceptable.

${ }^{6}$ There are only small and insignificant differences between these values and those for the original 2001 sample
} 
distribution plotted in Figure 1. To illustrate further the force of this, consider those who score on the bottom decile of the distribution of Depression-Enthusiasm. In this group, $33 \%$ reported that their job made them feel depressed much of, most of, or all of the time; this compares with just $2 \%$ for the rest of the population.

Job satisfaction also carries a negative skewness, signalling the presence of a minority of very or completely dissatisfied workers. More than a half (55\%) among the "very dissatisfied" or "completely dissatisfied" workers stated that their work made them feel depressed most of or all of the time, illustrating that these indicators are related as expected. In fact, job satisfaction is strongly correlated overall with DepressionEnthusiasm $(\rho=0.61)$, and somewhat less so with Anxiety-Comfort $(\rho=0.47)^{7}$

The table also shows that the sample mean values of both job satisfaction and the subjective well-being measures are greatest among those who later stayed in their jobs. That this is true of job satisfaction, and that the difference is significant at the $1 \%$ level, merely confirms the descriptive findings of many previous studies. In respect of Depression-Enthusiasm, the difference is also statistically significant at the $1 \%$ level, suggesting that the indicators may indeed be relevant as predictors of quitting. However, this judgement awaits an analysis that controls for other possible determinants of quitting. Descriptive statistics for the control variables, according to quitting status, are given in the Appendix, Table A2. In respect of Anxiety-Comfort, the difference between the means among quitters and stayers is not statistically significant at conventional levels ( $\mathrm{p}$ $=15 \%)$.

\footnotetext{
${ }^{7}$ Though accounting for these distributions is not the object here, it is worth reporting that very little of their variation is associated with industry or occupation; hence analysis of mobility effects are unlikely to be compounded by structural variations in turnover.
} 


\section{Findings.}

Making the assumption that the error terms in the latent quit propensity expressions are normally distributed, models (1) and (2) are estimated using the probit estimator. To allow for differential selection into the sample through attrition, the estimates allow for selection by both the observed controls and an unobserved term which could be correlated with any unobserved variables affecting the quit propensity. The models were estimated using the conventional Heckman maximum likelihood method, implemented using Stata version 11. Identification was achieved through the inclusion of two variables thought to affect the ability to locate respondents in the follow-up survey, namely whether the respondent gave an address of someone else who could be used to trace them in the event that they moved house, and whether there was a phone in the house.

Table 2 presents the core findings for the effect of subjective well-being at work on quitting. Looking first at column (1), it is shown that the sign of the correlation coefficient between the error terms of the well-being equation and the selection equation is negative; however, the $\chi^{2}$ statistic implies that the coefficient is imprecisely determined and is insignificantly different from zero. The key finding from this column is that there is a negative impact of Depression-Enthusiasm indicator on quitting, consistent with the prediction of Model (A). The size of the coefficient is such that, at the means of all the variables, a one standard deviation increase in well-being is estimated to lower the probability of quitting by 1.7 percentage points - in other words, a small but notable amount in comparison with the overall quit rate. ${ }^{8}$

Column (2) shows a similar finding: the Anxiety-Comfort index of job-related well-being can also explain quitting. However, the effect is weaker than with the Depression-

\footnotetext{
${ }^{8}$ The effect is computed as the product of the estimated marginal effect (taking selection into account) and the standard deviation given in Table 1 (0.818).
} 
Enthusiasm scale, as shown, both by the fact that the coefficient is statistically significant only at the $5 \%$ level, and by the poorer performance according to the two information criteria reported in the bottom two rows of the table. A one standard deviation rise in the Anxiety-Comfort index lowers the probability of quitting by just 1.00 percentage point.

In column (3) both scales are entered. It can be seen that only the Depression-Enthusiasm scale has an impact on mobility. The estimated impact on quitting is quite close to that obtained when only this scale is entered, and the estimated coefficient on the AnxietyComfort scale is very small and insignificant. Thus one can conclude that the AnxietyComfort scale's effect shown in Column (2) is probably derived from the fact that it is correlated with the Depression-Enthusiasm scale. On the Bayesian Information Criterion, of all the specifications discussed so far, that shown in column (1) with the DepressionEnthusiasm index is preferred. Its support for the negative predicted impact on quitting provides criterion validity for this indicator as a measure of well-being.

The full findings for this specification, including the selection equation, with estimated coefficient for all control variables, are given and discussed in the Appendix, Table A1. The control variables all have plausible estimated impacts on quitting, though by no means all coefficient estimates are statistically significantly different from zero. Whether or not the control variables are included in the equation does not alter the estimated coefficients on the key variables of interest, that is, the well-being indicators, by a statistically significant amount.

Table 3 gives the key findings from Model (B) incorporating overall job satisfaction. As can be seen from column (1), job satisfaction is negatively associated with quitting. This finding is entirely consistent with many previous studies. Here, the impact of a one standard deviation rise in job satisfaction is to lower the probability of quitting by 2.2 percentage points. However, the second research issue under investigation concerns, not 
so much whether job satisfaction is negatively related to quitting, but whether either or both of the well-being indicators constitute a better predictor than job satisfaction. The notable new finding is that the fit of Model (B) is no worse than, and if anything slightly better than, that for Model (A) obtained by using the Depression-Enthusiasm scale in column (1) of Table 2. The log likelihood is slightly though not significantly lower; and Model (B) would be selected according to either information criterion.

To investigate further, in column (2) of Table 3 both job satisfaction and the well-being scales are entered. The latter now each have small and insignificant effects on mobility, and together do not add significantly to the explanation of mobility. By contrast, the coefficient estimate on job satisfaction is only somewhat reduced, and by an insignificant amount, leaving it significantly negative. Model (B) is thus easily the preferred model.

Before concluding this section I consider some potential objections to the general pattern of findings. First, it might be held that workers on temporary contracts are in a special position and that links between their job mobility and either job satisfaction or well-being could be driving the result. In fact, temporary work contracts are relatively rare in Britain, and this is reflected in the current sample where $95.2 \%$ are on permanent contracts. Excluding the temporary contract workers from the sample led to only minor changes in the estimates.

Second, the findings so far are premised on the assumptions that I have made about the distributional form of the error terms, and on the particular definition used of quitting. To check whether the conclusions are robust, I have investigated also the sensitivity of the broad pattern of findings to changes in these assumptions. A first alternative is to treat differently those people who left their employer for a spell of unemployment (I call this the "unemployment group"), instead of making these as missing: one might instead categorise these as non-quitters. Doing so yields a similar pattern of findings to those 
shown in Tables 2 and 3. For example, the impact of a standard deviation rise in Depression-Enthusiasm scale now reduces the probability of quitting by 1.6 percentage points, little different from the previous result. A second alternative is to treat the unemployment group as a separate group, and to estimate the probability of falling into any one of three types: stayers, quitters and the unemployment group. Using the multinomial probit model to carry out such an estimation yields the same pattern of findings concerning the association of well-being or job satisfaction with quitting, with the well-being indices affecting the probability of being a quitter, but job satisfaction having the stronger effect.

A third potential objection is that the results shown in Tables 2 and 3 show only conditional correlation, not that any reduction in well-being or in job satisfaction causes quitting. This is a valid objection that applies also to the many previous studies of job satisfaction and quitting. It could be that there are unobserved factors which both stimulate quitting and lower well-being/job satisfaction. If so, one could not infer that any lowering of well-being or job satisfaction would lead to quitting, as with a classical treatment effect. Absent a defensible instrumental variable - one which in theory affects job satisfaction/well-being but not the quit propensity - one cannot rule out this objection. Absent a panel of data, one cannot eliminate unobserved fixed effects. Nevertheless, the current study makes a start on this issue by showing conditional correlation, and by controlling for a rich array of observed variables it is not unreasonable to see the causal explanation as a serious contender. ${ }^{9}$ Moreover, the criterion validity of

\footnotetext{
${ }^{9}$ The 2001 Skills Survey has a wide and varied array of job-related varables. In my presentation I have not encumbered the analysis with too many of these, preferring to include only conventional ones among the controls. Inclusion of many others made very little difference to the key estimates of the coefficients on well-being or job satisfaction.
} 
the job satisfaction variable is said to rest on the conditional correlation with subsequent quitting; the same applies to the well-being indicators. ${ }^{10}$

\section{Extension: non-linear effects.}

The analysis so far has assumed that well-being or job satisfaction affects the propensity to quit linearly: any given increase is assumed to lower quitting to the same extent, no matter where the starting point. In the early history of job satisfaction studies, however, a serious debate concerned whether job satisfaction and dissatisfaction had asymmetric properties. It was held that poor extrinsic job characteristics were likely to stimulate low job satisfaction, while high job satisfaction was affected by good intrinsic job characteristics such as the nature of the work itself (Herzberg et al., 1959). Non-linear patterns in the determination of job satisfaction or work-related well-being could be explained as arising from satiation in the impact of external stimulants. Non-linear patterns of behavioural response to job satisfaction are also part of the concern of recent studies of job-related well-being, which therefore look to develop separate measures for the negative and positive aspects of well-being (Warr and Parker, 2008). Non-linearity in the impacts of well-being on mobility might arise from threshold effects, whereby job search is stimulated only when well-being falls below a certain level. A deterioration from average to low well-being could engender remedial action in the form of quitting, while a similar change from above average to average might have less or no stimulus for job mobility. Similarly, movements up and down the job satisfaction scale may have asymmetric effects at each end of the scale.

\footnotetext{
${ }^{10}$ Another potential objection is that there could be some reverse causation, in that subsequent mobility might be anticipated and be the occasion for lower well-being or job satisfaction. However, this possibility seems more likely in the case of involuntary mobiliity associated with losing your job and becoming unemployed. Both endogeneity and reverse causation are serious endemic issues in the analysis of links between well-being or job satisfaction and contemporary workplace behaviours and performance.
} 
Table 4 investigates this possibility, and in this context provides a further comparison of models based on job satisfaction and those based on job-related well-being. Columns (1) examines the impact of either high or low well-being on the Depression-Enthusiasm scale, on quitting. As can be seen, low well-being, defined as being in the bottom quartile of the distribution, stimulates quitting. The computed marginal effect is such that low well-being raises quitting by more than 5.3 percentage points compared with those who have neither low nor high well-being. By contrast, for those with high well-being (top quartile) the coefficient estimate is small and not significantly different from zero. In short, the hypothesis that there is some asymmetry in the relationship between well-being and quitting is supported. It is primarily the quitting behaviour of those people who report that they are in the bottom tail of the negatively-skewed Depression-Enthusiasm distribution which is driving the result.

Column (2) provides a parallel result in respect of the Anxiety-Comfort measure, except that, as with Table 2, the result is weaker. The negative impact of having low well-being according to this measure is smaller, and only significant at the $10 \%$ level.

In column (3), the job satisfaction scale is divided up, and entered as high or low job satisfaction, with the reference category in the middle. As can be seen, an asymmetric pattern is again evident, with low job satisfaction explaining quitting behaviour. High job satisfaction has the expected sign, but is not quite statistically significant at the $10 \%$ level. Thus, it is also true of job satisfaction that it is primarily the bottom tail of the responses that is driving the negative impact on quitting.

Finally, columns (4) and (5) investigate whether, once low job satisfaction is included, the indicators for low well-being make any additional difference. It shows that low Depression-Enthusiasm is indeed associated with higher quitting, even when job 
satisfaction has been accounted for; while low Anxiety-Comfort has only a small and insignificant effect.

In considering all the specifications investigated, using the Bayesian Information Criterion which penalises the introduction of additional variables, the preferred model of quitting remains column (1) in Table 3 which includes simply job satisfaction; according instead to the Akaike Information Criterion, however, the non-linear formulation in column (4) of Table 4 is selected, including the indicators of low job satisfaction and low Depression-Enthusiasm.

\section{Conclusion.}

I have presented a simple validation test of two indices of job-related subjective wellbeing that are being used in psychological research, with a view to investigating whether these indices are also appropriate for use in labour market research. It is assumed that, if well-being indicators are to gain credence in labour economics they should be related to behaviour and to other variables in expected ways. While there is considerable evidence about the antecedents of different measures of well-being, studies of their consequences are relatively scarce, especially in the case of labour mobility. The findings are quite positive, supporting the use of these well-being indicators. In each case there is found to be a moderate negative association between the level of well-being and subsequent quitting, with the largest effect coming from the Depression-Enthusiasm scale. However, when combined it is only this scale that has a significant impact on mobility, suggesting that the impact of the Anxiety-Comfort scale derives from the fact that it is correlated, if imperfectly, with the Depression-Enthusiasm scale. In the best fit model involving wellbeing measures, a one standard deviation reduction along the Depression-Enthusiasm 
scale increases the probability of quitting by 1.70 points, which is approximately $19 \%$ of the actual quit rate. In addition the effect of Depression-Enthusiasm on involuntary mobility is small and insignificant. Thus, the evidence supports the use of the DepressionEnthusiasm scale, and provides an interest in finding which factors can promote greater well-being on this axis.

Nevertheless, my second finding is that an indicator of overall job satisfaction is unambiguously better at predicting quitting than either of the job-related well-being scales. The interpretation of this superior fit is that, despite the potential advantage of the well-being scales in covering the "arousal" as well as the "pleasure-displeasure" dimension of happiness, the evaluative nature of job satisfaction, whereby it compares the current job with outside opportunities, trumps the advantages of the well-being scales in the arena of mobility.

My third finding is that there is some asymmetry in the effects of both job satisfaction and job-related well-being on quitting. In particular, it is low levels of either that have the significant impacts; and in this asymmetric setting the Depression-Enthusiasm scale has explanatory power alongside job satisfaction.

Thus, despite the general superiority of the job satisfaction measure in anticipating quitting, one can conclude that job-related well-being could be a useful additional welfare measure for explaining mobility. Moreover the object of policy should be to target the level of well-being, not the difference between the current and outside levels which is arguably what job satisfaction measures. It remains an open question as to whether workrelated well-being measures will be better predictors than job satisfaction of internal performance indicators such as absenteeism, where the outside comparison is not so relevant. Moreover, occupational research is already finding discriminating patterns in the determinants of the varied dimensions of well-being and of job satisfaction. Other 
indicators are being developed and tested in micro settings. The objective of this strand of methodological research should be to arrive at good measures of well-being in which analyses and policies can be framed. Part of this research should be looking further into the labour market behavioural consequences of job-related well-being. 


\section{References}

Clark, A. E. (2001). "What Really Matters In A Job? Hedonic measurement using quit data." Labour Economics 8 (2): 223-242.

Clark, A. E., Y. Georgellis and P. Sanfey (1998). "Job Satisfaction, Wages and Quits: Evidence from German Panel Data." Research in Labor Economics 17 (95-121).

Elliott TE, Renier CM, Palcher JA. "Chronic pain, depression, and quality of life: correlations and predictive value of the SF-36." Pain Medicine 2003; 4:331-339.

European Commission (2002). Employment in Europe 2002, European Commission, Directorate-General for Employment and Social Affairs

Felstead, A., D. Gallie and F. Green (2002). Work Skills In Britain 1986-2001. Nottingham, DfES Publications.

Freeman, R. (1978). "Job satisfaction as an economic variable." American Economic Review. Papers and Proceedings 68 (2): 135-141.

Freeman, R. And J. L. Medoff (1984). What Do Unions Do? New York, Basic Books.

Green, F. And N. Tsitsianis (2005). "An investigation of national trends in job satisfaction in Britain and Germany." British Journal of Industrial Relations 43 (3): 401-429.

Green, F. (2006). Demanding Work. The Paradox of Job Quality in the Affluent Economy. Woodstock, Princeton University Press.

Hamermesh, D. (1977). Economic Aspects of Job Satisfaction. Essays in Labor Market Analysis. Edited by O. Ashenfelter and W. Oates. New York, John Wiley: 5372.

Hardy, G. E., Woods, D., and Wall, T. D. (2003). The impact of psychological distress on absence from work. Journal of Applied Psychology, 88, 306-314.

Herzberg, F., B. Mausner and B. Snyderman (1957). The Motivation To Work. New York, John Wiley.

Kahneman D., and Riis J. (2005). Living, and thinking about it: Two perspectives on life. In F.A. Huppert, N. Baylis \& B. Keverne (Eds.), The science of well-being (pp. 285-304). Oxford: Oxford University Press

Kristensen, N. And E. Johansson (2008). "New evidence on cross-country differences in job satisfaction using anchoring vignettes." Labour Economics 15 (1): 96-117.

Levy-Garboua, L. And C. Montmarquette (2004). "Reported job satisfaction: what does it mean?" Journal of Socio-Economics 33: 135-151.

Levy-Garboua, L., C. Montmarquette and V. Simonnet (2007). "Job satisfaction and quits." Labour Economics 14 (2): 251-268.

Russell, J. A. (2003). "Core Affect and the Psychological Construction of Emotion." Psychological Review 110 (1): 145-172.

Totterdell, P., S. Wood and T. Wall (2006). "An intra-individual test of the demandscontrol model: A weekly diary study of psychological strain in portfolio workers." Journal of Occupational and Organizational Psychology 79 (1): 63-84. 
Warr, P. (1990). "The measurement of well-being and other aspects of mental health." Journal of Occupational Psychology 63: 193-210.

Warr, P. (2007). Work, Happiness, and Unhappiness. London, Lawrence Erlbaum Associates.

Warr, P. And S. Parker (2008). The measurement of job-related affect: a questionnaire for general use, University of Sheffield, mimeo.

Weir, M., Ed. (1976). Job satisfaction: challenge and response in modern Britain. London, Fontana/Collins.

Wright, T. A. And R. Cropanzano (1998). "Emotional Exhaustion as a Predictor of Job Performance and Voluntary Turnover." Journal of Applied Psychology 83 (3): 486-493. 


\section{Appendix.}

This appendix presents in Table A1 the full estimation results for the specification summarised in column (3) of Table 2. The estimated coefficients for the control variables changed little between the different runs of Tables 2 and 3, so only the current one is presented and discussed.

Control variables conventionally found in mobility studies are used in the specification, and they have largely the expected associations with mobility. The propensity to quit follows a U-shape with age, reaching its lowest point at approximately the age 50. It also follows a U-shape with job tenure, reaching its lowest point after 285 months; however, as usual this effect cannot be assumed to be causal, since job tenure is endogenous. Living as a couple lowers the quit propensity, especially for women. Union recognition also reduces mobility, consistent with the union voice theory (Freeman and Medoff, 1984). Being better educated, being non-white, living in a high unemployment area, or working for a large establishment or in the public sector each appear to have no significant impact on quitting. Some of these variables also figure in the determinants of selection in the sample, including age and partnership. Also of note is the significant impact of two identifying variables: inclusion in the sample is less likely among those who presented a contact address in case of moving (all were asked to do so), or who had no phone.

Table A2 gives the descriptive statistics for the control variables. 
Table 1 Job-Related Well-Being and Job Satisfaction

\begin{tabular}{|c|c|c|c|}
\hline & $\begin{array}{l}\text { Depression- } \\
\text { Enthusiasm }\end{array}$ & $\begin{array}{l}\text { Anxiety- } \\
\text { Comfort }\end{array}$ & Job Satisfaction \\
\hline \multicolumn{4}{|l|}{ Mean } \\
\hline All & 4.357 & 3.760 & 4.222 \\
\hline Quitters & 4.142 & 3.640 & 3.742 \\
\hline Stayers & 4.377 & 3.771 & 4.267 \\
\hline Standard Deviation & 0.818 & 0.921 & 1.189 \\
\hline Skewness & -0.575 & -0.024 & -0.932 \\
\hline \multicolumn{4}{|l|}{ Correlation coefficients: } \\
\hline Depression-Enthusiasm & 1 & & \\
\hline Anxiety-Comfort & 0.604 & 1 & \\
\hline Job Satisfaction & 0.612 & 0.470 & 1 \\
\hline
\end{tabular}

1473 observations.

$\dagger$ The interval was approximately 15 months, but varied between individuals depending on the date of the first interview.

Data Source: Postal follow-up sample of the 2001 Skills Survey. Base: employees in Britain aged 40 to 60 . 
Table 2 Well-Being and Quitting

\begin{tabular}{lccc}
\hline & $(1)$ & $(2)$ & $(3)$ \\
Depression-Enthusiasm & $-0.225^{* * *}$ & & $-0.229^{* * *}$ \\
& $(0.0560)$ & & $(0.0715)$ \\
Anxiety-Comfort & & $-0.125^{* *}$ & 0.00569 \\
& & $(0.0539)$ & $(0.0683)$ \\
Controls & Yes & Yes & Yes \\
Log Likelihood & -1384 & -1391 & -1384 \\
$\rho$ & -0.581 & -0.597 & -0.589 \\
$\chi^{2}$ & 1.209 & 1.371 & 1.267 \\
AIC & 2834.7 & 2847.5 & 2838.6 \\
BIC & 3018.7 & 3031.5 & 3033.7 \\
\hline
\end{tabular}

Maximum likelihood probit estimates with sample selection.

Robust standard errors in parentheses

$* * * \mathrm{p}<0.01, * * \mathrm{p}<0.05, * \mathrm{p}<0.1$

For control variables see Table A1, which gives the full specification estimates for Model (3).

All specifications use 1473 uncensored observations.

Table 3 Job Satisfaction, Well-Being and Quitting

\begin{tabular}{lcc}
\hline & $(1)$ & $(2)$ \\
Job Satisfaction & $-0.173^{* * *}$ & $-0.137 * *$ \\
Depression-Enthusiasm & $(0.0423)$ & $(0.0596)$ \\
& & -0.122 \\
Anxiety-Comfort & & $(0.0822)$ \\
& & 0.0372 \\
Controls & & $(0.0705)$ \\
Log Likelihood & Yes & Yes \\
$\rho$ & -1383 & -1380 \\
$\chi^{2}$ & -0.577 & -0.572 \\
AIC & 1.459 & 1.455 \\
BIC & 2832.4 & 2833.2 \\
\hline
\end{tabular}

Notes:

Maximum likelihood probit estimates with sample selection.

Robust standard errors in parentheses

$* * * \mathrm{p}<0.01, * * \mathrm{p}<0.05, * \mathrm{p}<0.1$

For control variables see Table A1.

All specifications use 1473 uncensored observations. 
Table 4 Well-Being, Job Satisfaction and Quitting: Testing for Asymmetry.

\begin{tabular}{|c|c|c|c|c|c|}
\hline High D-E $\uparrow$ & $\begin{array}{c}(1) \\
0.0124 \\
(0.118)\end{array}$ & (2) & (3) & (4) & (5) \\
\hline Low D-E $\uparrow$ & $\begin{array}{c}0.465 * * * \\
(0.124)\end{array}$ & & & $\begin{array}{c}0.304 * * \\
(0.125)\end{array}$ & \\
\hline High A-C $\uparrow$ & & $\begin{array}{r}-0.0549 \\
(0.129)\end{array}$ & & & \\
\hline Low $\mathrm{A}-\mathrm{C} \uparrow$ & & $\begin{array}{l}0.195^{*} \\
(0.118)\end{array}$ & & & $\begin{array}{l}0.0385 \\
(0.124)\end{array}$ \\
\hline High Job Satisfaction & & & $\begin{array}{c}-0.164 \\
(0.104)\end{array}$ & & \\
\hline Low Job Satisfaction $\$$ & & & $\begin{array}{c}0.565^{* * *} * \\
(0.162)\end{array}$ & $\begin{array}{c}0.466^{* * * *} \\
(0.178)\end{array}$ & $\begin{array}{c}0.621 * * * \\
(0.173)\end{array}$ \\
\hline Log Likelihood & -1384 & -1390 & -1382 & -1379 & -1384 \\
\hline$\rho$ & -0.592 & -0.637 & -0.552 & -0.522 & -0.537 \\
\hline$\chi^{2}$ & 1.248 & 1.725 & 1.416 & 1.138 & 1.306 \\
\hline AIC & 2837.4 & 2849.5 & 2834.4 & 2828.1 & 2837.7 \\
\hline $\mathrm{BIC}$ & 3032.5 & 3044.6 & 3030.0 & 3023.2 & 3032.9 \\
\hline
\end{tabular}

Notes:

Maximum likelihood probit estimates with sample selection.

Robust standard errors in parentheses

$* * * \mathrm{p}<0.01, * * \mathrm{p}<0.05, * \mathrm{p}<0.1$

$\dagger$ High (low) D-E defined as top (bottom) quartile of the Depression-Enthusiasm scale; the middle two quartiles form the residual category. Multinomial logit estimates. $* * * p<0.01$, ** $\mathrm{p}<0.05, * \mathrm{p}<0.1$. Control variables as in Table A1.

+ "Completely satisfied" or "very satisfied"; $+\uparrow$ "fairly dissatisfied", "very dissatisfied" or "completely dissatisfied"; reference category is: "fairly satisified" or "neither satisfied nor dissatisfied".

All specifications use 1473 uncensored observations. 
Table A1 Full Specification for Table 2, Model (3)

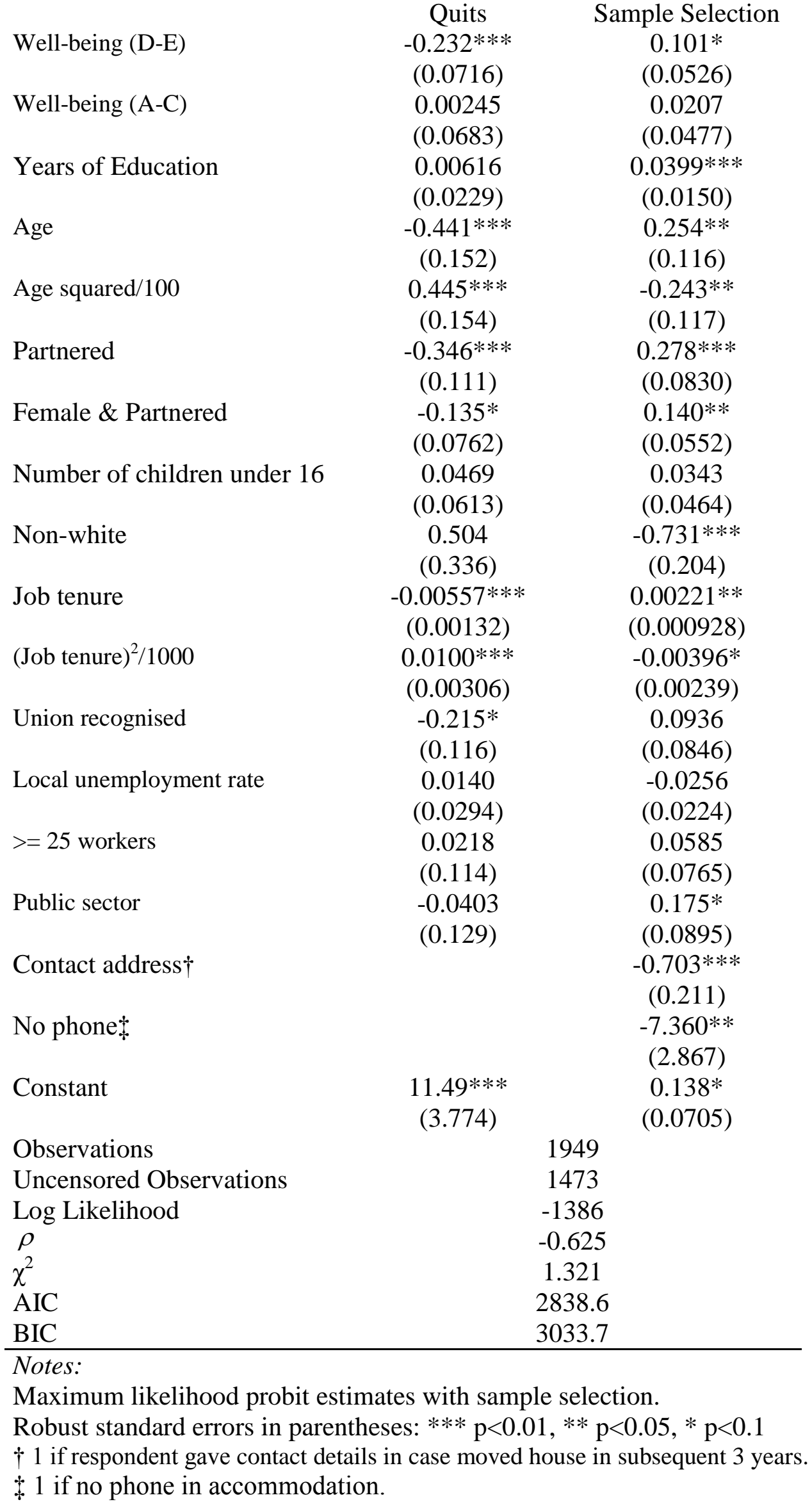


Table A2. Mean Values for Control Variables.

\begin{tabular}{|l|c|c|c|}
\hline & Quitters & Stayers & All \\
\hline Years of Education & 12.128 & 12.469 & 12.158 \\
\hline Age & 48.87 & 48.016 & 48.795 \\
\hline Age squared/100 & 24.183 & 23.426 & 24.117 \\
\hline Partnered & 0.83 & 0.76 & 0.824 \\
\hline Female and Partnered & 0.423 & 0.276 & 0.41 \\
\hline Number of children under 16 & 0.54 & 0.746 & 0.558 \\
\hline Non-white & 0.02 & 0.032 & 0.021 \\
\hline Job tenure (months) & 138.6 & 96.4 & 134.9 \\
\hline Job tenure squared/1000 & 32.592 & 21.383 & 31.612 \\
\hline Union recognised & 0.555 & 0.439 & 0.545 \\
\hline Local unemployment rate & 3.094 & 3.104 & 3.095 \\
\hline$>=25$ workers & 0.678 & 0.677 & 0.678 \\
\hline Public sector & 0.384 & 0.335 & 0.38 \\
\hline
\end{tabular}


Figure 1 Kernel Density of Job-Related Well-Being Scales
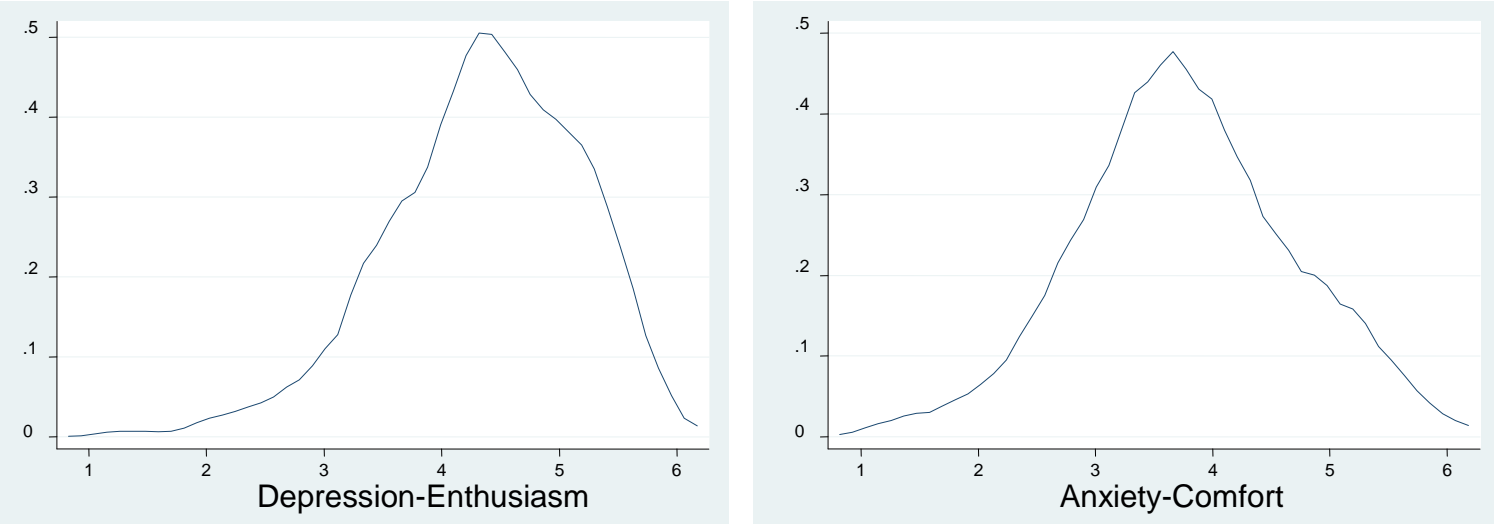

Note: Kernel $=$ Epanechnikov . 